\title{
Duas novas espécies de Enchenopa Amyot \& Serville (Hemiptera, Membracidae) do semi-árido do Estado da Paraíba, Brasil ${ }^{1}$
}

\author{
Rembrandt Romano de A. Dantas Rothéa ${ }^{2}$ \& Antonio José Creão-Duarte ${ }^{3}$
}

\author{
${ }^{1}$ Trabalho realizado com o apoio do Programa Ecológico de Longa Duração (PELD) \\ ${ }^{2}$ Bolsista CNPq.rradr@terra.com.br \\ ${ }^{3}$ Programa de Pós-Graduação em Ciências Biológicas, Universidade Federal da Paraíba, Campus I, 58059-900 João Pessoa-PB, Brasil. \\ diretoria@ccen.ufpb.br
}

\begin{abstract}
Two new species of Enchenopa Amyot \& Serville (Hemiptera, Membracidae) from the semi-arid region of Paraiba State, Brazil. Enchenopa euniceae sp. nov. and E. minuta sp. nov. (both from São José dos Cordeiros, Paraíba, Brasil) are described and illustrated.
\end{abstract}

KEYWORDS. Caatinga, Homoptera, Membracinae, new species, taxonomy.

RESUMO. Duas novas espécies de Enchenopa Amyot \& Serville (Hemiptera, Membracidae) do semi-árido do Estado da Paraíba, Brasil. Enchenopa eunicea sp. nov. e Enchenopa minuta sp. nov. (ambas de São José dos Cordeiros, Paraíba, Brasil ) são descritas e ilustradas.

PALAVRAS-CHAVES. Caatinga, Homoptera, Membracinae, novas espécies, taxonomia.

O gênero Enchenopa foi descrito por Amyot \& Serville, 1843 para acomodar Membracis monoceros Germar, 1818. É um dos maiores gêneros de Membracini, com 24 espécies válidas (McKamey, 1998). As espécies são muito parecidas entre si, diferindo apenas no tamanho e coloração. As características da genitália dos machos pouco ajudam, dadas às semelhanças de suas estruturas. Conseqüentemente, a identificação torna-se difícil, muitas vezes somente com a comparação com o exemplar-tipo, ou por meio de fotografias dos mesmos.

Duas espécies são descritas com base em exemplares coletados na Reserva Particular do Patrimônio Natural, Fazenda Almas, município de São José dos Cordeiros, região de semiárido (Caatinga) do Estado da Paraíba, Brasil.

Abreviaturas: DSE - Departamento de Sistemática e Ecologia; UFPB - Universidade Federal da Paraíba.

\section{Enchenopa euniceae sp. nov.} (Fig. 1)

Diagnose. Tégminas castanho-escuras com duas manchas amareladas: a primeira, semicircular, situada na metade basal das tégminas, a segunda na metade apical e, entre as duas, uma faixa transversal escura.

Medidas (em milímetros). Fêmea/macho. Comprimento total 7,63/5,77; comprimento do pronoto 6,46/4,40; comprimento da cabeça 1,18/0,93; largura da cabeça 2,15/1,86; altura do pronoto 2,29/1,79; distância entre os ângulos umerais 2,54/2,04.

Holótipo fêmea. Coloração geral castanho-escura, ligeiramente avermelhada. Superfície do corpo recoberta com cerdas diminutas, mais adensadas no metopídio e na região pós-clipeal. Ocelos mais próximos dos olhos que entre si. Cabeça quadrangular com a porção distal do pós-clípeo ligeiramente mais escura e com cerdas mais longas. Pronoto com processo anterior tão longo quanto a sua largura na base, dirigido para frente, discretamente para cima, e com três pares de carenas laterais: a primária estendida do ápice do processo até às proximidades da margem lateral do pronoto; as duas secundárias situadas na base do processo, logo abaixo da carena primária. Processo posterior tectiforme, com a extremidade aguda, alcançando a altura do ápice da quinta célula apical das tégminas. Carena mediana distinta, sendo foliácea no contorno do processo anterior. Tíbias anteriores e medianas foliáceas, as posteriores com cerdas cuculadas nas fileiras I e II. Tégminas castanho-escuras com duas manchas amareladas: a primeira, semicircular, situada na metade basal, ocupando o espaço entre a veia Radial e o clavo; a segunda, na metade distal, ocupando a terceira, a quarta e a quinta células apicais; e, entre as duas, uma faixa transversal escura. Abdome castanho-escuro.

Macho. Semelhante à fêmea, porém, menor, com o processo anterior mais curto e podendo, em alguns espécimes, estar praticamente ausente.

Holótipo fêmea. Brasil, Paraíba."Faz[enda]. Almas, S[ão]. José dos / Cordeiros (PB), 7²8' S/ 36 53' W, 650m, Caatinga, / 21-22.II.2004, Rothéa \& / Evangelista Col." (DSE/UFPB). Parátipos: 3 fêmeas com os mesmos dados do holótipo; 3 fêmeas e 4 machos, ibidem "1617.IV.2004, Gindomar/ \& Creão Col." (DSE/UFPB); 12 fêmeas e 1 macho, ibidem "03-04.V.2003, Rothéa \&/ Creão Col." (DSE/UFPB); 2 fêmeas e 1 macho, ibidem "08-09.III.2003, Rothéa \& Creão Col.". (DSE/UFPB); 4 fêmeas e 4 machos, ibidem "10.X.2004, Rothéa \& Creão Col." (DSE/UFPB); 5 fêmeas e 4 machos, ibidem "1011.III.2005, Rothéa \& Creão Col.” (DSE/UFPB).

Comentários. A coloração da cabeça, da superfície inferior 

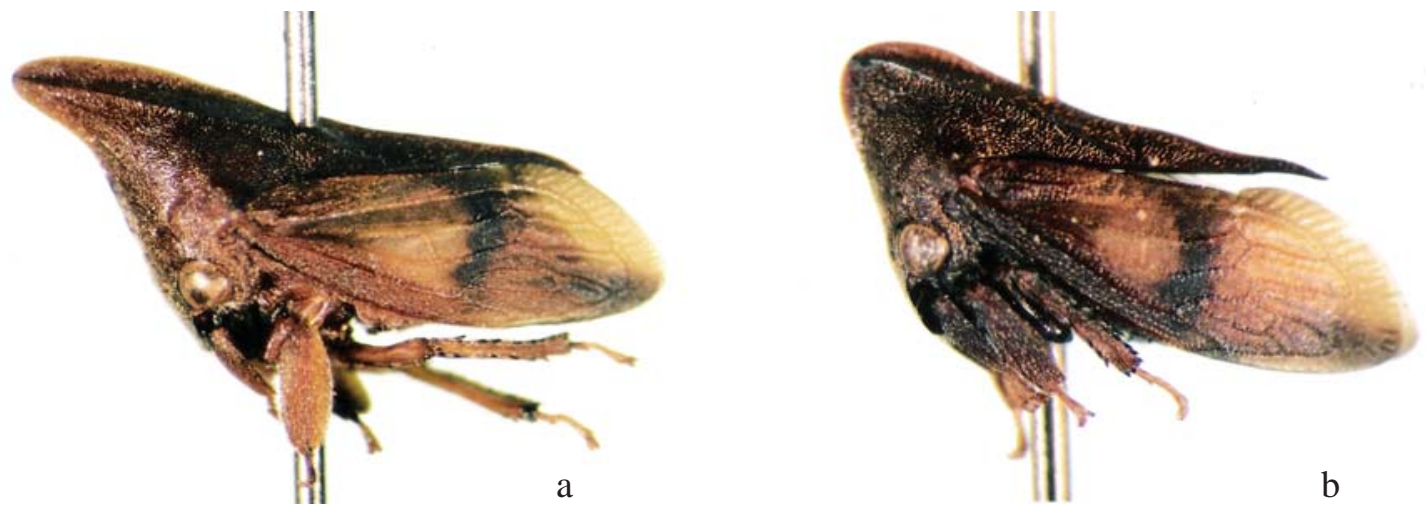

Fig. 1. Enchenopa euniceae sp. n. a - Holótipo fêmea; b - Parátipo macho.

do tórax e dos fêmures pode ser mais escura que a do restante do corpo, chegando à tonalidade preta, tanto nos machos como nas fêmeas. Os exemplares foram coletados, principalmente, sobre Indigofera suffruiticosa Mill (Leguminosae, Papilionoideae) e, também, sobre Phaseolus sp. (Fabaceae) e Senna spectabilis (DC.) (Cassieae).

O nome da espécie é dado em homenagem à Professora Eunice Braz, proprietária da Reserva Particular do Patrimônio Natural, Fazenda Almas, São José dos Cordeiros, Paraíba, Brasil.

\section{Enchenopa minuta sp. nov.}

(Fig. 2)

Diagnose. Coloração geral castanho-amarelada, com a cabeça e superfície inferior do tórax ligeiramente mais escuras. Segundo par das valvas do ovopositor com a extremidade lisa e dois "dentes" na superfície dorsal, cuja distância entre eles é menor que a largura da valva.

Medidas (em milímetros). Fêmea/macho. Comprimento total 6,12/5,01; comprimento do pronoto 5,20/4,14; comprimento da cabeça 1,11/0,99; largura da cabeça 1,67/1,55; altura do pronoto 2,23/1,55; distância entre os ângulos umerais 1,92/1,73.
Holótipo fêmea. Coloração geral castanho-amarelada; cabeça e superfície inferior do tórax ligeiramente mais escuras. Cabeça sub-quadrangular com cerdas diminutas. Pós-clípeo de contorno semi-circular com cerdas longas na extremidade. Ocelos mais próximos dos olhos que entre si. Pronoto com processo anterior ligeiramente mais longo que a sua largura na base, dirigido para frente e para cima, e com três pares de carenas: a carena primária estendida desde o ápice do processo anterior até as proximidades da margem lateral e as duas secundárias situadas na base do processo anterior, logo abaixo da carena primária. Processo posterior tectiforme, com a extremidade estreitando-se abruptamente, alcançando a altura do ápice da quinta célula apical das tégminas. Carena mediana bem desenvolvida e foliácea em quase toda sua extensão. Tégminas com a metade basal ligeiramente mais coriácea que a metade apical; venação distinta com uma veia transversal $\mathrm{r}$ $\mathrm{m}$ e duas $\mathrm{m}$-cu; cinco células apicais e duas discoidais. Pernas anteriores e medianas com tíbias foliáceas; as posteriores com cerdas cuculadas bem desenvolvidas nas fileiras I e II. Tarsos amarelados; os posteriores ligeiramente mais longos que os demais. Abdome cônico, curto, não indo além do ápice do processo posterior.

Macho. Menor, com processo anterior geralmente curto,
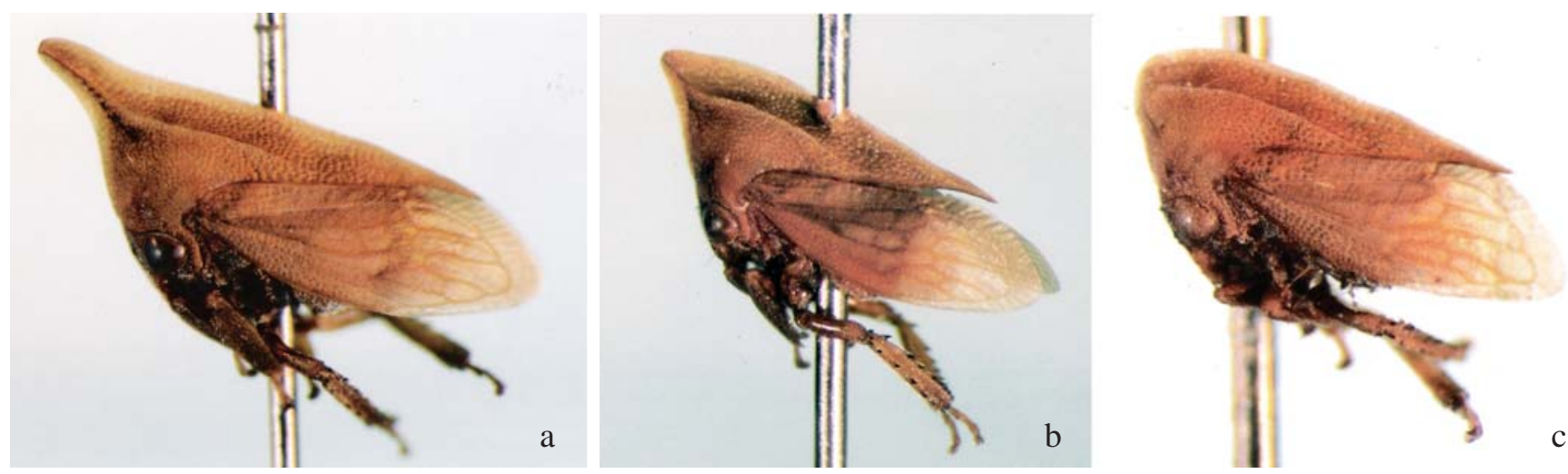

Fig. 2. Enchenopa minuta sp. n. a - Holótipo fêmea; b, c - Parátipos machos. 
podendo, em alguns casos, estar reduzido a uma saliência angulosa.

Holótipo fêmea. Brasil, Paraíba. "Faz[enda]. Almas, S[ão]. José dos / Cordeiros (PB), 7 $7^{\circ} 28^{\prime} \mathrm{S} / 36^{\circ} 53^{\prime} \mathrm{W}, 650 \mathrm{~m}$, Caatinga, / 1011.III.2005, Rothéa Col.” (DSE/UFPB). Parátipos: 16 fêmeas e 1 macho com os mesmos dados do holótipo; 21 fêmeas e 3 machos, ibidem "06.XII.2004, Rothéa Col." (DSE/UFPB).

Comentários. A cabeça e a superfície inferior do tórax, tanto nas fêmeas como nos machos, podem se apresentar com tonalidade escura, quase preta. A espécie aproxima-se de $E$. concolor (Fairmaire, 1846) diferindo desta no tamanho menor.

Os exemplares foram coletados sobre Phaseolus sp.
(Fabaceae) e Serjania glabrata Kunth (Burseraceae), principalmente na primeira planta.

\section{REFERÊNCIAS}

Amyot, C. J. B. \& Serville, A. 1843. Histoire Naturelle des Insectes - Hemiptères. Deuxième partie. Homoptères. Homoptera Latr. Librairie Encyclopèdique de Roret, Paris, France, p. 455676.

McKamey, S. H. 1998. Taxonomic Catalogue of the Membracoidea (Exclusive of Leafhoppers). Second Supplement to Fascicle 1Membracidae of the General Catalogue of the Hemiptera. Memoirs of the American Entomological Institute. Gainesville, 60: 1377.

Recebido em 11/05/2006; aceito em 24/01/2007 